\title{
Structural Behavior of Pipelines Buried in Expansive Soils under Rainfall Infiltration (Part I: Transverse Behavior)
}

\author{
Mohammed Bouatia ${ }^{a, b^{*}}$, Rafik Demagh $^{\mathrm{a}}$, Zohra Derriche ${ }^{\mathrm{c}}$ \\ ${ }^{a}$ LGC-ROI, Laboratoire de Génie Civil-Risques et Ouvrages en Interaction, University of Batna 2-Mostefa Ben Boulaid, 0578 Batna, \\ Algeria. \\ ${ }^{b}$ Department of Geotechnics and Transportation, School of Civil Engineering, Faculty of Engineering, Universiti Teknologi Malaysia, \\ 81310 UTM Johor Bahru, Johor, Malaysia. \\ ${ }^{c}$ LTPiTE, Laboratoire Travaux Publics, ingénierie des Transports Environnement, Ecole Nationale Supérieure des Travaux Publics, \\ 16051 Algiers, Algeria.
}

Received 25 May 2020; Accepted 08 August 2020

\begin{abstract}
Landslides, fault movements as well as shrink/swell soil displacements can exert important additional loadings on soil buried structures such as pipelines. These loadings may damage the buried structures whenever they reach the strength limits of the structure material. This paper presents a two-dimensional plane-strain finite element analysis of an $800 \mathrm{~mm}$ diameter water supply pipeline buried within the expansive clay of the Ain-Tine area (Mila, Algeria), considering the unsaturated behavior of the soil under a rainfall infiltration of $4 \mathrm{~mm} /$ day intensity and which lasts for different time durations ( 8,15 and 30 days). The simulations were carried out using the commercial software module SIGMA/W and considering different initial soil suction conditions P1, P2, P3 and P4. The soil surface heave and the radial induced forces on the pipeline ring (i.e., Axial $F_{A}$, Shear $F_{S}$ forces and bending moments $M_{B}$ ) results indicated that following the changes of suction the rainfall infiltration can cause considerable additional loads on the buried pipeline. Moreover, these loads are proportionally related to the initial soil suction conditions as well as to the rainfall infiltration time duration. The study highlighted that the unsaturated behavior of expansive soils because of their volume instability are very sensitive to climatic conditions and can exert adverse effects on pipelines buried within such soils. As a result, consistent pipeline design should seriously consider the study of the effect of the climatic conditions on the overall stability of the pipeline structure.
\end{abstract}

Keywords: Finite Element Analysis; Unsaturated Soil; Buried Pipeline; Rainfall Infiltration; Suction; Radial Internal Forces.

\section{Introduction}

Buried pipelines are important lifeline infrastructures used by many countries and companies to transport fluids (i.e., water or gas) to remediate the strong hydraulic and energy resources inequalities over the world. The geotechnical and structural engineers faced many challenges to safely and durably design and build these budgetconsuming projects. Landslides, fault movements as well as shrink/swell soil displacements can exert important additional loadings on structures especially for pipelines buried within expansive soils. These loadings may damage these structures or disturb their normal operations whenever their magnitudes reach the strength limits of the structure material.

* Corresponding author: m.bouatia@univ-batna2.dz

http://dx.doi.org/10.28991/cej-2020-03091585

(C) 2020 by the authors. Licensee C.E.J, Tehran, Iran. This article is an open access article distributed under the terms and conditions of the Creative Commons Attribution (CC-BY) license (http://creativecommons.org/licenses/by/4.0/) 
In recent decades, professional and academic forensic surveys have revealed that the unsaturated behavior of expansive soils is the main cause of the reported damages that occurred on many types of structures such as lightweight structures and buildings [1,2], water transport canals used in agriculture activities [3]. Severe damages were reported also on buried pipelines $[4,5]$ in many parts of the world such as arid and semi-arid regions, as a result of deformations induced by volume changes that characterize expansive soils $[6,7]$.

It is known that arid and semi-arid areas, are usually characterized, by a deep water table and by extremely dry surface soils which bear negative pore water pressures (suction) [8] and which are extremely sensitive to wetting and drying. When these soils are expansive, the supply of a tiny quantity of water may develop within these soils important swelling deformations as well as important swelling pressures when the deformations are blocked. The mechanical characteristics (i.e., shear strength and deformation parameters) of the soils located above the water table are inversely related to the moisture content which increases the sensitivity of these soils to the climate conditions such as rainfall [9-11]. Han et al. [12] describe the suction as an energy potential that takes the form of a tension stress which is exerted on the soil skeleton, this potential keeps, together, the soil particles in packets, offering more resistance of the soil against deformations.

Rainfall precipitation or irrigation activities provide a downward water flow in the expansive soil increasing its moisture content and reducing its suction simultaneously, and consequently provokes volume changes which are measured as vertical displacements on the ground surface of such types of soil $[10,13,14]$. The volume changes that occur in the pipeline embedding soil provoke loading forces on the structure of the pipeline that can endanger the stability of the lifeline infrastructure. The unsaturated behavior effects on pipeline response have been analyzed both experimentally and numerically as well as under different loading conditions (i.e., landslides, faults movements ...).

Experimental large scale tests have been conducted by Randeniya et al. [15] to investigate deformations of a steel pipeline buried in an unsaturated clayey soil under different saturation conditions; they found that the backfill soil's degree of saturation can considerably control pipeline deformations. Full-scale tests and finite element simulations were carried out by Robert et al. [16]. They found that the unsaturated soil strength and stiffness increase with soil suction and externally imposed ground movements increase lateral loads on pipelines. Huang et al. [17] have conducted a full scale analysis of the effect of the frost heave on a $105 \mathrm{~m}$ long and $0.9 \mathrm{~m}$ diameter chilled gas pipeline with $35 \mathrm{~m}$ long was buried in permafrost in Alaska. They found that the pipelines buried in the arctic region suffer damages due the induced soil vertical movements which principally take the form of bending actions causing strains on the pipeline bodies.

In which concern numerical studies, a finite element analysis has been conducted by Rajeev and Kodikara [18] and Robert and Soga [19]. The obtained results showed that the reduction in suction due to the increase in moisture content provokes an increase of the soil loading on the buried structures such as pipelines. In this direction, an interesting study about the background of pipelines have been undertaken by Al-Khazaali et al. [20] that can be used as a good platform to do pipeline-soil interaction researches in unsaturated mediums. Moreover, the response of buried pipelines under strike-slip fault movements have been studied by Vazouras et al. [21] and Oghabi et al. [22]. Saadeldin et al. [23] investigated through a parametric study the influence of the moisture content variations on the longitudinal movements of a hypothetical pipeline of $6 \mathrm{~m}$ length and $0.15 \mathrm{~m}$ diameter that occurred due to change in suction by considering different boundary conditions. The transverse soil-pipeline system deformations associated with trenching was studied by Al-Khazaali et al. [20] considering the effect of the groundwater table (GWT) level and that of the depth of excavation. This study helps to define the safe combination (GWT, Depth) when trenching near to buried pipeline in unsaturated soils.

All the previous studies highlighted the importance of taking into consideration the unsaturated behaviour of the expansive embedding soils which can cause important additional loadings on the buried structures considering the longitudinal response of the pipelines.

To address the substantial hydrological inequalities that characterize the eastern side of Algeria, more than $600 \mathrm{~km}$ of water supply pipelines supplying water from the Beni-Haroun dam, were buried in the Mila basin (Mila province, Algeria), a region known by its semi-arid climate [24] and famous as a highly sensitive region to shrink/swell movements [25]. In recent years, many of the water transport pipelines have suffered repetitive damages in north of Algeria taking the form of leakage points along the pipeline route. During the rainy season the problem worsens and the leakage rate recorded increases. Unfortunately, after the construction of the Beni-Haroun dam in 2006 (i.e., the largest dam in Algeria, Mila province), the Algerian Ministry of Water Resources received several investigation reports on the damages that occurred on the water supply pipelines which are experiencing many leakage points along their routes. The site named Aine-Tine is one of the reported cases. Forensic studies indicated that the cause is mainly related to the interaction between these buried structures with the expansion of the clayey soils of Mila basin where large areas have been classified by Athmania et al. [25] as high sensitive to the shrink/swell phenomena (see Figure 1). The Aine-Tine site located in Aine-Tine municipality is crossed by an $800 \mathrm{~mm}$ diameter water supply pipeline which carries water to more than 12 municipalities of the Mila province. 
The serious economic and environment effects of these damages highlight the importance of taking into consideration the unsaturated behavior of such soils during the design and the construction of pipelines in Algeria. The safety and durability of buried pipeline-systems necessitate careful design studies which need to take into account all of the probable contributing factors related to the materials (i.e., soil and pipeline), environment (i.e., freezing, drying and wetting cycles) and loading (i.e., overburden stresses, traffic) to study the behavior of pipelines usually buried in the vadose zone (i.e., above the water table) at 2 to $3 \mathrm{~m}$ from the ground surface in order to predict and reduce the possible damage of the structures.

In this study, a Finite Element Analysis has been conducted using the commercial software SIGMA/W to assess the pipeline structural response expressed in terms of radial induced axial force $F_{A}$, shear force $F_{S}$ and bending moment $M_{B}$ that are exerted on the pipeline perimeter following the expansive soil volume change provoked by a 4 $\mathrm{mm}$ /day rainfall infiltration event lasting for 30 days (i.e., 1 month). The present study aims to understand the effect soil wetting on the pipeline/unsaturated-soil interaction by considering (1) different rainfall time durations and (2) the initial soil suction conditions. The water supply pipeline coming from the Beni-Haroun Dam of $800 \mathrm{~mm}$ diameter buried at $2 \mathrm{~m}$ depth in Aine-Tine (Mila, Algeria) expansive soil was used in this numerical analysis. First, this article begins with an introduction which presents a summary of the literature on previous pipeline-soil interaction studies and the background and goals of the present study followed by a presentation of the methodology used to perform the analysis and then an overview of the SIGMA/W finite element software used in this investigation. Following a detailed description of the main features of the Aine-Tine area the numerical model adopted (geometry and boundary conditions) the material characteristics used to simulate Aine-Tine expansive soil and pipeline structure are exposed. Finally, the results obtained are presented and discussed where conclusions and future works are proposed at the end of this study.

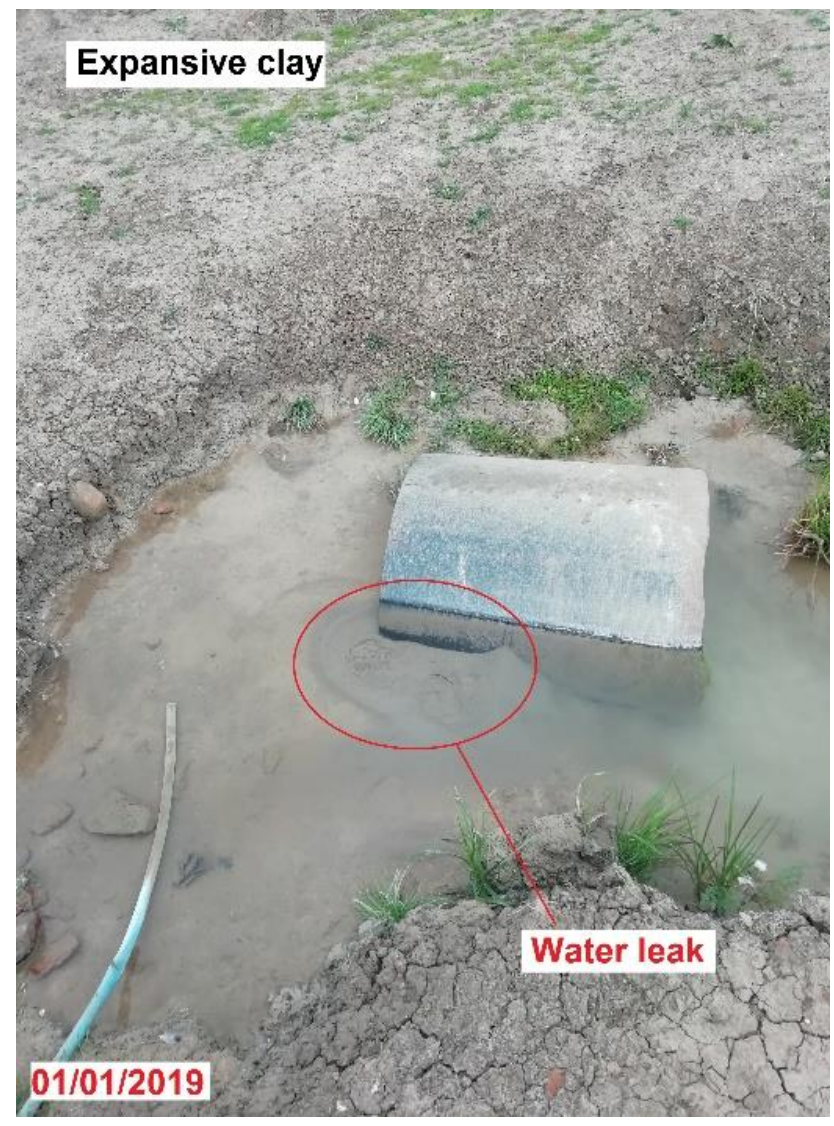

Figure 1. Water leakage point at Aine-Tine site

\section{Research Methodology}

Pipelines are linear structures used for transporting fluids such as gas and liquids. They are usually buried in various types of soils over long distances and can cross through areas with high sensitivity to expansion. In the present work, a two-dimensional numerical simulation is performed to analyse the transverse structural behaviour of a buried pipeline following expansion movements due to rainfall precipitation. The paper is a contribution to help engineers to predict reasonably what are the probable reasons that cause several water leakage points and which constitute continuous disturbance of the water supply process. The main steps of the numerical analysis are summarized in the flowchart bellow (see Figure 2): 


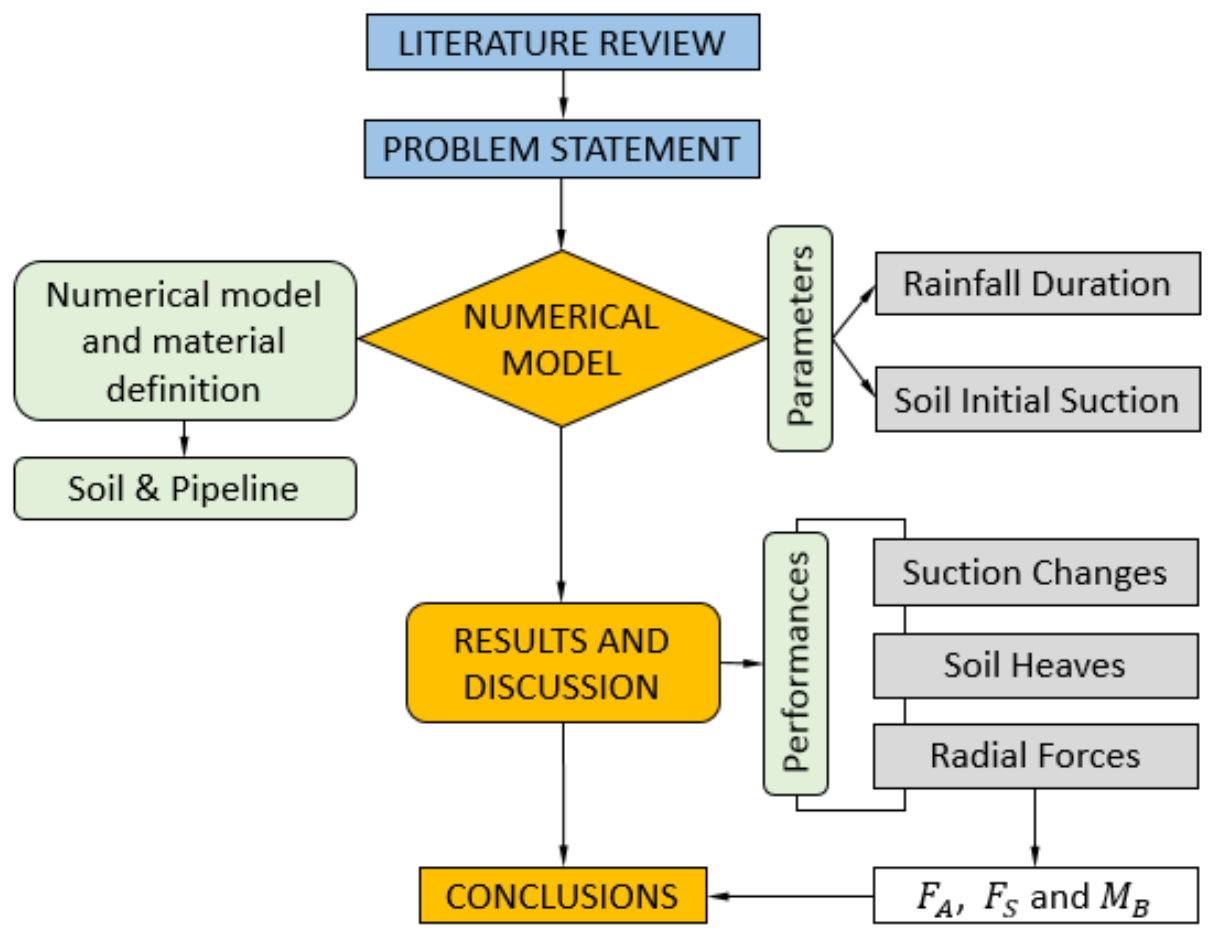

Figure 2. Research flowchart of the present paper

\section{The Study Area}

The study area is located in the Mila province in the North-East of Algeria (see Figure 3) which belongs to the eastern Alpine chain of the north of Algeria. It is north bordered by the Skikda and Jijel Provinces, south by the Batna Province, West by the Setif province and by the Constantine province in the East. It is situated at $490 \mathrm{~km}$ from Algiers (i.e., the capital of the country) and at about $60 \mathrm{~km}$ from the city of Constantine. Mila covers an area of 3,550 km2, composed by five communes (towns) and a number of 32 municipalities. The Aine-Tine site can be bracketed by latitudes $06^{\circ} 18^{\prime} 30^{\prime \prime}$ and $06^{\circ} 19^{\prime} 00$ and longitudes $36^{\circ} 25^{\prime} 30^{\prime \prime}$ and $36^{\circ} 25^{\prime} 45^{\prime \prime}$. Geologically, Mila's exposure soil consists of Mio-Pliocene and Quaternary continental deposits which covers a set of carbonate, bedrock, of Cretaceous to Eocene ages. More than $70 \%$ of the geological formations are Alluviums and clays, where these occupy $50.14 \%$ and $21.83 \%$, respectively [25].

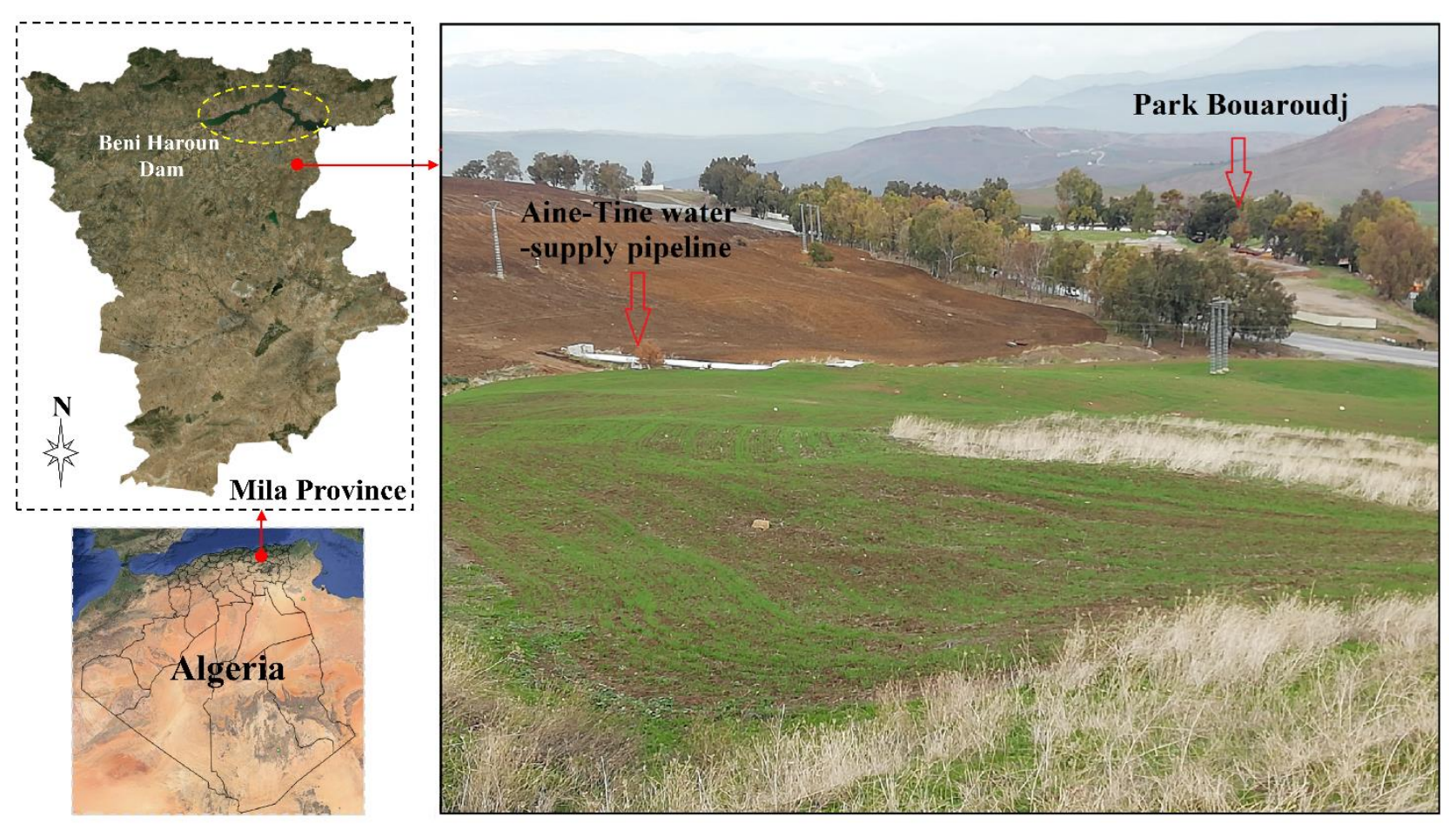

Figure 3. Aine-Tine area location 
The study area belongs to the semi-arid climate region of the country that receives precipitation below potential evapotranspiration, but not as low as the desert climate. The semi-arid climate is characterized by only two seasons: a hot dry season in summer and a cold rainy season in winter. Detailed investigations of the hydrological properties of the eastern side of Algeria have been presented by Mebarki [26]. The annual average precipitation in Mila province is $678.5 \mathrm{~mm} /$ year, even though in 1984 the maximum annual precipitation reached $1058 \mathrm{~mm}$. The maximum monthly average is between 120 and $145 \mathrm{~mm} / \mathrm{month}$ (i.e. December). During the period October to April, December is the rainiest month of the Mila region. It must be stressed that Mila is a geotechnical problem prone area (i.e., landslides and a shrink/swell movements). Rainfall precipitation is the principal trigger of these phenomena which occur especially during the wet season. This is due to the high sensitivity of clayey soils related to the decrease in suction following precipitations. Site investigation results indicated the water table level has been found to be located at about $15 \mathrm{~m}$ depth which is consistent with the data reported in [26].

\section{Finite Element Analysis using SIGMA/W}

The present study is a two-dimensional plane-strain numerical simulation of the soil-pipeline-environment interaction. The powerful 2D finite element SIGMA/W software was used. SIGMA/W is one of the modules of GEOSTUDIO software suite proposed by GeoSlope International Ltd. [27]. The suite is usually used for modeling stresses and deformations in ground and structural materials. The SIGMA/W module is widely used for geotechnical research and practice by civil and mining communities to carry out slope stability, consolidation, shrinkage/swelling and structural analysis in both saturated and unsaturated conditions ([28-30]). In our case, it is used here to investigate the transverse structural behavior of a steel pipeline buried in a high expansive soil considering the unsaturated behavior of the soil.

Similar 2D software programs (Plaxis 2D, FLAC 2D) can equally be used to carry out the present study. When comparing SIGMA/W and Plaxis 2D, it must be indicated that both give similar and conservative results due to the assumption of plane strain modeling. SIGMA/W is more flexible and faster than Plaxis 2D. Its software library contains linear, nonlinear, elastic and elastoplastic soil constitutive models to simulate soils with different meshing options controlling the form (i.e., triangle, square or combination between both) and the global size with possibility of refining. Plaxis 2D on the other hand, provides five mesh resolutions which can be applied (very coarse, coarse, medium, fine and very fine). As for the boundary conditions and loading options SIGMA/W makes it possible to consider constant values as for the usual $\mathrm{x}$, y fixities or functions (i.e., spline, linear or step function) of time to simulate environment conditions such as precipitation or seismic actions. SIGMA/W gives also the possibility to model structures such as pipelines and retaining walls using bar and beam elements. The partial differential force equilibrium and water continuity equations are the two fundamental equations which govern the mechanical behavior of soil and flow behavior of the water phase in unsaturated soils, respectively [29]. These two equations are incorporated into SIGMA/W, which simplifies the two-dimensional saturated and unsaturated hydromechanical analyses. The unsaturated behavior of soils is governed by an incremental stress-strain relationship developed by Fredlund and Rahardjo [8] where it is a function of the net normal stress $\left(\sigma-u_{a}\right)$ and the suction $\left(u_{a}-u_{w}\right)$ as stress state variables. Shear strength and stiffness of unsaturated soil are functions of these two stress state variables. The two-dimensional matrix formulation of the stress-strain relationship incorporated in SIGMA/W is as follows:

$$
\left\{\begin{array}{c}
\Delta \varepsilon_{x} \\
\Delta \varepsilon_{y} \\
\Delta \gamma_{x y}
\end{array}\right\}=\frac{1}{E}\left[\begin{array}{ccc}
1 & -\mu & 0 \\
-\mu & 1 & 0 \\
0 & 0 & 2(1+\mu)
\end{array}\right]\left\{\begin{array}{c}
\Delta\left(\sigma_{x}-u_{a}\right) \\
\Delta\left(\sigma_{y}-u_{a}\right) \\
\Delta\left(\tau_{x y}\right)
\end{array}\right\}+\frac{1}{H}\left[\begin{array}{ccc}
1 & 0 & 0 \\
0 & 1 & 0 \\
0 & 0 & 1
\end{array}\right]\left\{\begin{array}{c}
\Delta\left(u_{a}-u_{w}\right) \\
\Delta\left(u_{a}-u_{w}\right) \\
\Delta\left(u_{a}-u_{w}\right)
\end{array}\right\}
$$

Where $\varepsilon_{x}, \varepsilon_{y}$ and $\gamma_{x y}$ are the normal and shear strain components, $\sigma_{x}, \sigma_{y}$ and $\tau_{x y}$ are the normal and shear stress components, $E$ is the Young's modulus of the soil structure. $H$ is the elasticity modulus with respect to a change in suction and $\mu$ is the Poisson's ratio. $H$ is estimated adopting the relationship $H=E /(1-2 \mu)$ according to Vu and Fredlund $[14,31]$ published works. SIGMA/W helps users to consider automatically the additional shear strength of unsaturated soils evolving from the suction by extending the Mohr-Coulomb failure criterion as shown in Equation 2.

$\tau_{f}=c^{\prime}+\left(\sigma-u_{a}\right) \tan \varphi^{\prime}+\left(u_{a}-u_{w}\right) \Theta \tan \varphi^{\prime}$

Where $\Theta$ is the normalized volumetric water content VWC or $\left[\left(\theta_{w}-\theta_{r}\right) /\left(\theta_{s}-\theta_{r}\right)\right]$ where $\theta_{r}$ is the volumetric water content at residual state, $\theta_{s}$ is the volumetric water content at saturated state. Modeling of the unsaturated behavior requires the definition of the hydraulic property functions of the soil, which are the soil-water characteristic curve SWCC and the permeability function $K$ which relates the volumetric water content and the hydraulic conductivity to the soil suction. The calculation of the variation of unsaturated modulus of elasticity $\left(E_{\text {unsat }}\right)$ due to the change in saturation state of the soil is possible using the incorporated function which defines the modulus of elasticity as a function of effective stress or suction (see Section 6.3) which takes into account changes in pore water pressures under precipitation, irrigation activities or rising of GWT. In addition to the van Genuchten [32] model of the SWCC 
included in Plaxis 2D, the used software includes the Fredlund and Xing [33] model and allows users to define their own soil water characteristic curve. Additionally, unlike others similar 2D geotechnical software's (i.e., Plaxis2D or FLAC2D), SIGMA/W allows practitioners to define and combine geometries and analyze multiple geotechnical problems in a single modeling project and to solve analyses in parallel which considerably reduces simulation times.

\section{Numerical Model}

\subsection{Model Geometry}

A uniform soil profile is assumed to extend down to $4 \mathrm{~m}$ depth under the ground level with a length of $8 \mathrm{~m}$ horizontally, as shown in Figure 4. The horizontal and vertical dimensions of the model are set to avoid the effects of boundary conditions. These dimensions are related directly to the pipeline diameter where according to the recommendations presented in many published researches ([21, 22, 34]) it was found after simulations that it is sufficient to numerically evaluate induced large displacements on pipeline transverse cross section by having a crosssection model with 10 and 5 times the pipe diameter for horizontal and vertical dimensions, respectively. On the basis of these recommendations the present study was carried out adopting the model dimensions shown in Figure 4.
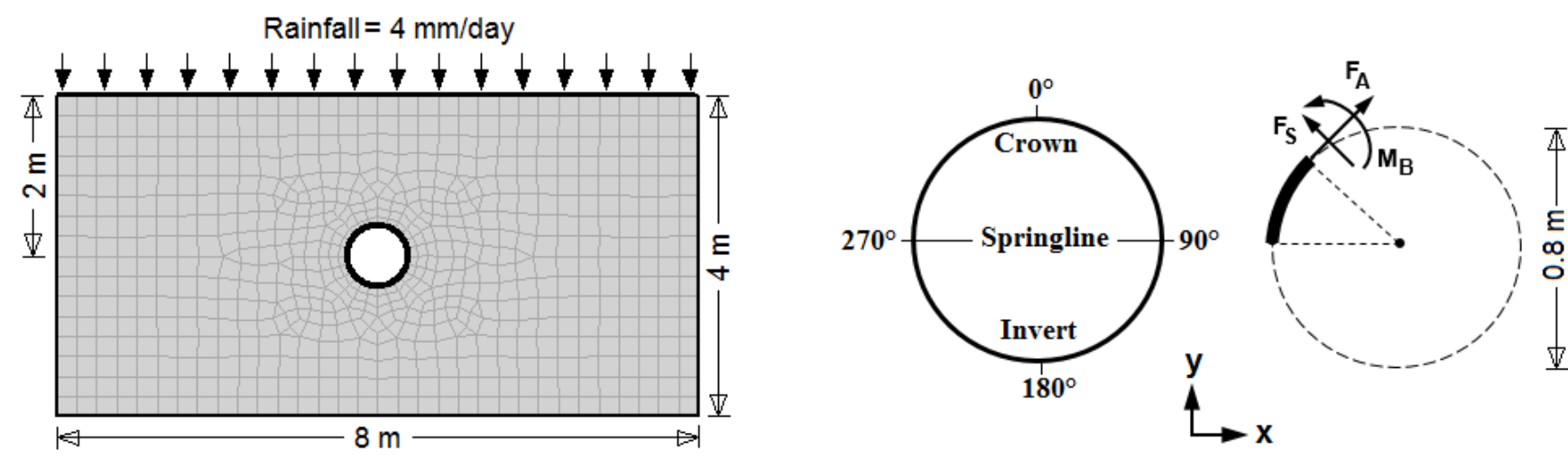

Figure 4. Finite element model and pipeline cross-section detail

The meshes were generated automatically using the available option in SIGMA/W quadrilateral and triangles elements where a unified mesh size of $0.25 \mathrm{~m}$ was applied for the soil region. For the pipe, the beam element perimeter is divided into 24 equal segments, which gives an angle increment of $15^{\circ}$ for each segment. The length s of each segment can be obtained by applying the following equation $s=r . \theta$ (i.e. $0.104 \mathrm{~m}$ ) where $\mathrm{r}$ is the radius of the pipeline and $\theta$ is the angle. The total number of elements in the model is equal to 690 elements.

\subsection{Boundary Conditions}

The boundary conditions of the model are: left and right boundaries are fixed only in the $\mathrm{x}$-direction and the bottom boundary is fixed both in the $\mathrm{x}$ and y directions. To model the rainfall effect, a $4 \mathrm{~mm} /$ day constant rainfall unit flux $q$ $(\mathrm{mm} /$ day) lasting for 30 days, which corresponds to the minimum daily average occurring in the rainiest month in the Mila basin (i.e., December) was assigned to the top surface of the model. As for the suction, the boundary conditions are given in Figure 5. To study the effect of suction, four initial profiles of suction P1, P2, P3 and P4 are imposed on the model based on the assumption of a hydrostatic linear distribution of the suction above the water table to simplify the study. The imposed suction profiles may correspond to different water table levels or reflect different degrees of surface evapotranspiration that characterize arid and semi-arid climate regions such as Mila province. The theoretical water table levels corresponding to the suction profiles P1, P2, P3 and P4 are equal to 15, 30, 60 and $120 \mathrm{~m}$, respectively. The first profile corresponds to the Aine-Tine area water table depth which gives a suction value at the top surface of the model equal to $147 \mathrm{kPa}$ (see Figure 5). The other profiles are obtained by a double increment way $(\mathrm{P} 1=1 / 2 \mathrm{P} 2, \mathrm{P} 2=1 / 2 \mathrm{P} 3$ and P3=1/2 P4). Therefore, four pressure head values equal to $-11,-26,-56$ and $-116 \mathrm{~m}$ are, respectively, maintained along the bottom boundary nodes of the model for each suction profile during the rainfall simulation. 

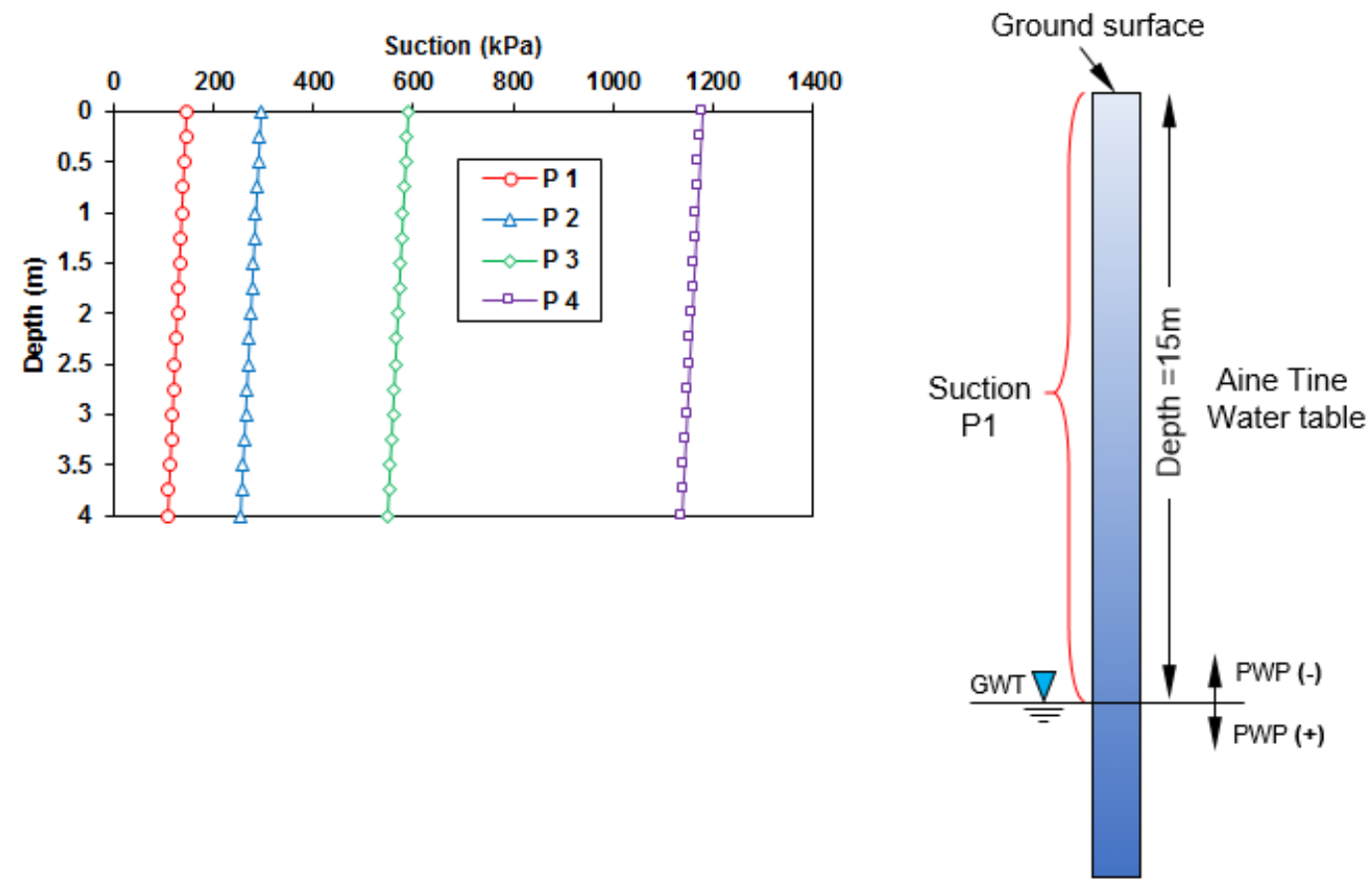

Figure 5. The profiles of initial suction conditions P1, P2, P3 and P4 and Aine-Tine water table details

\section{Material Characteristics}

\subsection{Clay}

The pipeline is buried in the vadose zone of the Aine-Tine area which is classified according to USCS classification system as $\mathrm{CH}$, which is an inorganic clay of high plasticity with a clay content equal to $52 \%$. The geotechnical parameters of Aine-Tine clay are presented in Table 1. They were summarized from in situ and laboratory investigation reports of soil studies carried out on the Aine-Tine site between the years 2015 and 2017. The integrated extended elastic-perfectly plastic Mohr-Coulomb (MC) constitutive model was used to model the clayey soil. It is successfully used to analyze soil-pipeline interaction problems considering the unsaturated behavior of the soil [16, 19, 20]. The gravity is set to $9.81 \mathrm{~m} / \mathrm{s}^{2}$.

Table 1. Aine-Tine clay geotechnical parameters

\begin{tabular}{ccc}
\hline Material & Soil property & Value \\
\hline Particle size distribution $(\%)$ & Sand=26, Silt=22, Clay $=52$ \\
Atterberg limits $(\%)$ & $w_{L}=65.32$, & $w_{P}=27.87, I_{P}=37.45$ \\
Void ratio $e$ & 0.69 \\
Total unit weight $\gamma_{t}\left(\mathrm{KN} / \mathrm{m}^{3}\right)$ & 19.1 \\
Dry unit weight $\gamma_{d}\left(\mathrm{KN} / \mathrm{m}^{3}\right)$ & 15.7 \\
Aine-Tine Clay & Natural moisture content $w_{\text {nat }}(\%)$ & 22 \\
& Elastic modulus $E_{\text {sat }}(\mathrm{kPa})$ & 1000 \\
Poisson's ratio $\mu$ & 15 \\
Angle of internal friction $\varphi\left({ }^{\circ}\right)$ & 22 \\
Cohesion $C(\mathrm{kPa})$ & $5 \mathrm{e}-3$ \\
& Saturated permeability $K_{\text {sat }}(\mathrm{m} / \mathrm{day})$ & $\mathrm{CH}$, Inorganic clay of high plasticity \\
\hline
\end{tabular}

\subsection{Hydraulic Property Functions, SWCC and K}

Physical parameters such as particle size distribution and plasticity indices are the main factors that determine the shape of the soil water characteristic curve (SWCC). An estimation of the SWCC function was carried out based on literature reviews where the similarity of the index properties was considered as the criterion of selection amongst 
many published soil results around the world. The estimated $S W C C$ has been found to be close to that of the Regina clay presented in $[13,29,35]$ papers. Using Pedo-Transfer prediction options available in SIGMA/W software such as the van Genuchten [32] and Fredlund and Xing's [33] methods, the SWCC can be estimated. In the present study, the van Genuchten model shown in Equation 3 was used to estimate the SWCC using the particle size distribution data and the plasticity index results shown in Table 1.

$S=S_{r}+\frac{1-S_{r}}{\left[1+\left(\frac{u_{a}-u_{w}}{a}\right)^{n}\right]^{m}}$

Where $\mathrm{S}$ is the degree of saturation, $\left(\mathrm{u}_{\mathrm{a}}-\mathrm{u}_{\mathrm{w}}\right)$ is the suction, $S_{r}$ is the residual saturation and a, $\mathrm{n}$, and $\mathrm{m}$ are fitting parameters where $n=1 /(1-m)$. The corresponding van Genuchten [32] values of these parameters used in this study are as follow: $\mathrm{a}=0.5, \mathrm{n}=1.08$. The pore water movement is governed by the soil permeability function $K$. Using the SWCC and the saturated permeability $K_{s a t}$, The permeability function $K$ was generated based on the van Genuchten method [32] method which is integrated in the GeoStudio software suite library. $K_{\text {sat }}$ is assumed to be $5 \times 10^{-3} \mathrm{~m} /$ day.

\subsection{Modulus of Elasticity Variation with Respect to Suction}

Many researchers have reported the dependency between soil stiffness and the suction value $\left(u_{a}-u_{w}\right)[15,36$, 37]. Oh et al. [36] proposed a semi-empirical model to predict the unsaturated Young's modulus $E_{\text {unsat }}$ of unsaturated cohesionless soils as shown in Equation 4 using the saturated elastic modulus $E_{\text {sat }}$ and two fitting parameters. The extended model by Adem and Vanapalli [38] to cover all types of soils, was utilized in this study.

$E_{\text {unsat }}=E_{\text {sat }}\left[1+\alpha \frac{\left(u_{a}-u_{w}\right)}{\left(P_{a} / 101.3\right)}(S)^{\beta}\right]$

Where $P_{a}$ is the atmospheric air pressure and $\alpha$ and $\beta$ are fitting parameters. In this analysis, the fitting parameters $\alpha$ and $\beta$, are taken equal to 2 and 0.1 , respectively. The chosen values of $\alpha$ and $\beta$ are appropriate for fine-grained expansive soils (i.e., clay) as confirmed by Adem and Vanapalli [38, 39].

\subsection{Pipeline}

Different diameter sizes of water transport pipelines are buried in Mila Basin. The analyzed section of pipeline buried in Aine-Tine site is $800 \mathrm{~mm}$ diameter and has a diameter-to-thickness ratio equal to 40 and assumed to be covered by $2 \mathrm{~m}$ clayey soil. The pipeline ring was modeled as a beam element using the linear elastic model. The behavior of the steel pipeline is governed by its rigidity, which is a function of its geometry dimensions and elastic modulus. The elastic modulus is assumed to be $2 \mathrm{GPa}$ which corresponds to a flexible pipeline classification. The Aine-Tine pipeline characteristics are summarized in Table 2. Figure 4 shows the cross section used to calculate the moment of inertia that is essential for transverse pipeline simulations in the case of 2D plane-strain analysis. The interface between the pipeline and the soil was created using line area option. The interface was modeled using the same characteristics of the surrounding clayey soil presented in Table 1.

Table 2. Aine-Tine pipeline parameters

\begin{tabular}{ccc}
\hline Material & Soil property & Value \\
\hline & External diameter $Q_{\text {ext }}(\mathrm{mm})$ & 800 \\
Aine-Tine Pipeline & Thickness t (mm) & 20 \\
& D/t & 40 \\
& Young's modulus E (GPa) & 2 \\
\hline
\end{tabular}

\section{Results and Discussion}

The numerical analyses were conducted to simulate the effect of the volume changes that occur in the expansive soil subjected to a saturation process acting as an external hydraulic loading (i.e., rainfall precipitation) on the buried pipeline. The results are presented in terms of induced (1) heave and deformations and (2) internal forces that apply along the ring of the pipeline following the decrease of soil suction. The rainfall time duration is taken into account by considering the results of four chosen time durations equal to 4, 8, 15 and 30 days of simulation and four initial suction profiles were studied to consider the effect of the initial suction (i.e., P1, P2, P3 and P4). 


\subsection{Suction Variations}

Rainfall infiltration provides a downward flux which increases the water content of the soil and decreases consequently the suction (i.e. negative pore water pressure) of the soil. In this study, the effect on the suction of the rainfall that occurs during the rainiest month (December) in Mila basin is modelled. For the four initial suction profile conditions P1, P2, P3 and P4, the suction variations were evaluated as transient seepage analysis under $4 \mathrm{~mm} / \mathrm{day}$ rainfall infiltration using SIGMA/W software where the hydraulic response is governed by the soil water characteristic curve $S W C C$ and the permeability function $K$.

Figure 6 presents the variation of the suction profiles at the outer edges of the model in response to the wetting process throughout the simulation periods. It can be noticed that the soil suction decreases gradually starting from the top surface going to the bottom of the soil depth. And proportionally with time as shown for each chosen time duration of simulation $0,4,8,15$ and 30 days. Figure $6 \mathrm{a}, 6 \mathrm{~b}, 6 \mathrm{c}$ and $6 \mathrm{~d}$ are presented to provide a comparison where it is obvious that the higher the initial suction profile (P1, P2, P3 and P4), the higher the range of suction fluctuations. Similarities of the hydraulic response were obtained in many published studies [14, 31, 40].

(a)

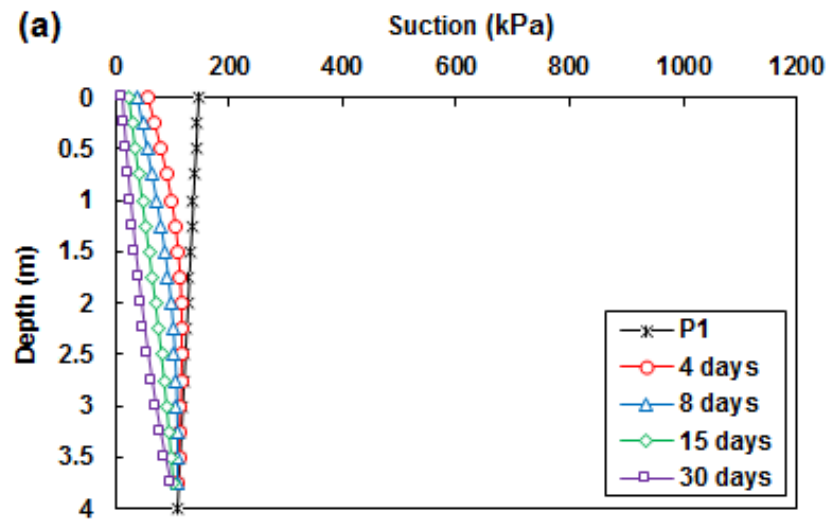

(c)

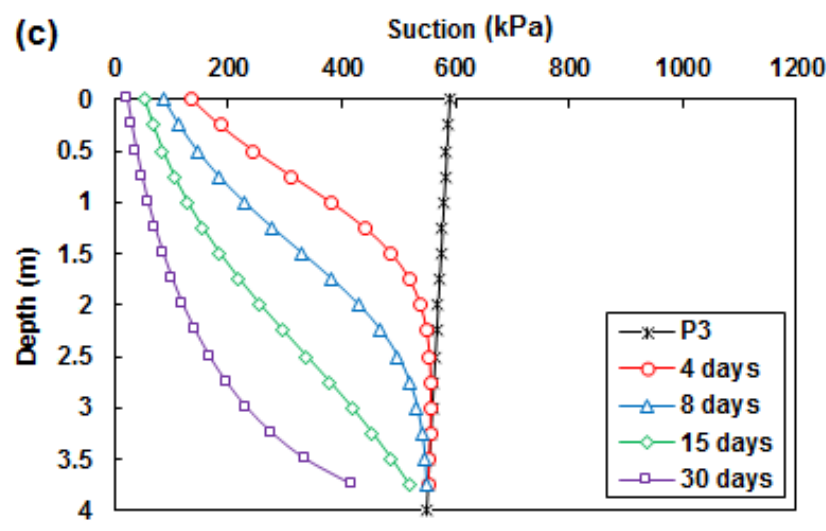

(b)

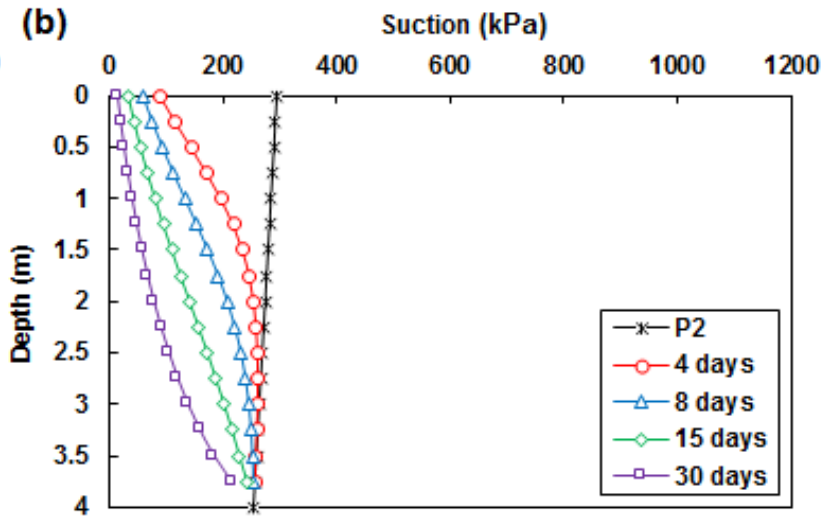

(d)

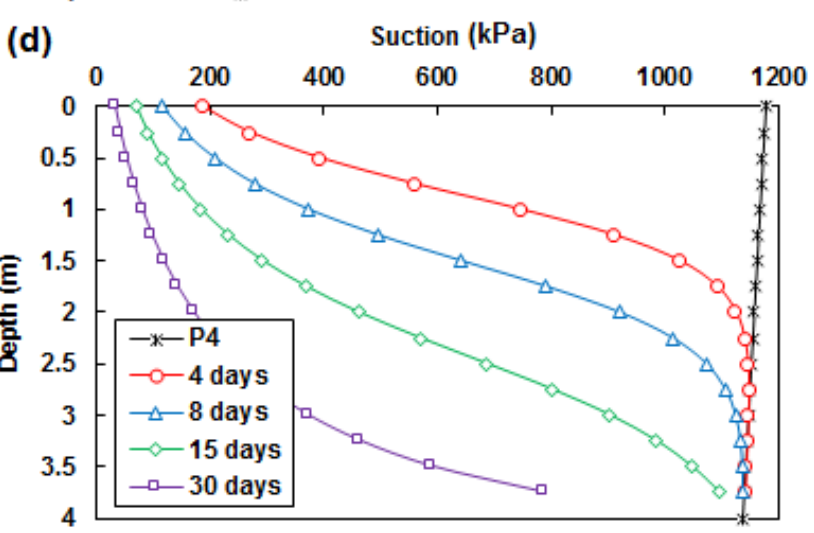

Figure 6. Evolution of soil suction with rainfall time for the suction profiles P1, P2, P3 and P4

\subsection{Soil Volume Changes (Heave)}

The induced decrease of suction discussed in the above section leads to volume changes associated with deformations within the soil. Figure 7 depicts the contours of vertical displacements, for the whole model, after 30 days of $4 \mathrm{~mm} /$ days rainfall intensity for different initial suction profile conditions P1, P2, P3 and P4 presented, respectively, in Figure $7 \mathrm{a}, 7 \mathrm{~b}, 7 \mathrm{c}$ and $7 \mathrm{~d}$. The direction and magnitude of soil deformations can be viewed by the red arrow vectors for which the ascending vertical direction dominates the movements. The final calculated displacements at the top surface of the model, crown and invert of the pipeline are illustrated in Figure 8 where those obtained at the top surface are equal to $1.54,2.01,3.81$ and $8.51 \mathrm{~cm}$ which correspond to the suction profiles P1, P2, P3 and P4, respectively, while those calculated at the crown of the pipeline are as follow $0.54,0.82,1.80$ and $4.24 \mathrm{~cm}$. Besides, matching proportionality between heave and decrease of soil suction have been obtained by Rajeev and Kodikara [18] during their experimental and numerical investigations on the effect of swell movements on buried pipelines following the moisture content increase to saturation level within the soil due to a succession of capillary rises. Figures 7a, 7b, 7c and $7 \mathrm{~d}$ are presented to provide a comparison at the end of the simulation (30 days) where it can be observed that the higher the initial suction the higher the induced heave at the upper surface of the model. The magnitudes of heave decrease with depth where the ratios of the vertical displacements at the crown of the pipeline with those at the top surface of the model are equal to 35, 41, 47 and 50\% which correspond to P1, P2, P3 and P4, respectively. 

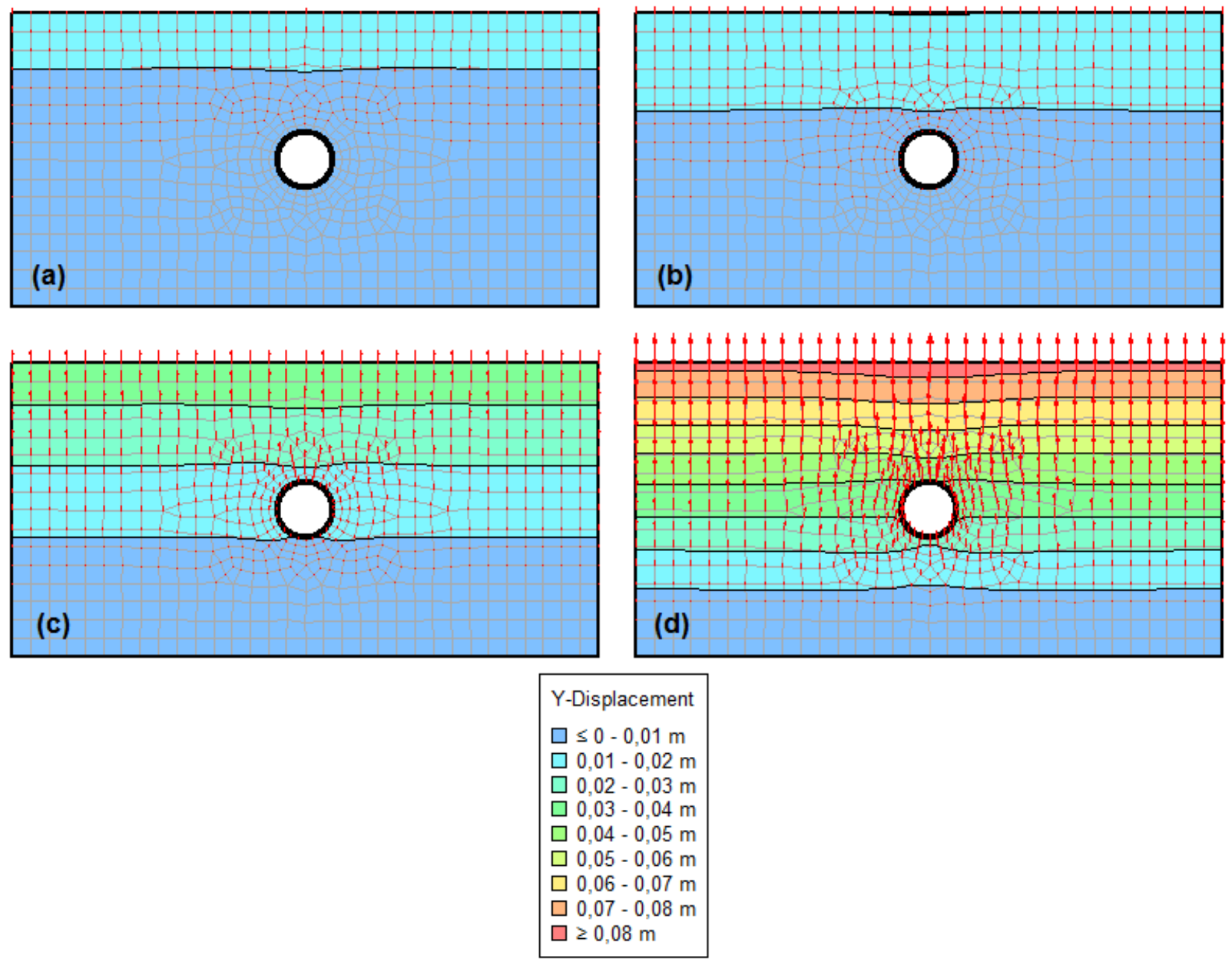

Figure 7. Vector and maximum displacements at the crown of the pipeline and at the top surface of the model for different initial suction after 30 days of rainfall infiltration

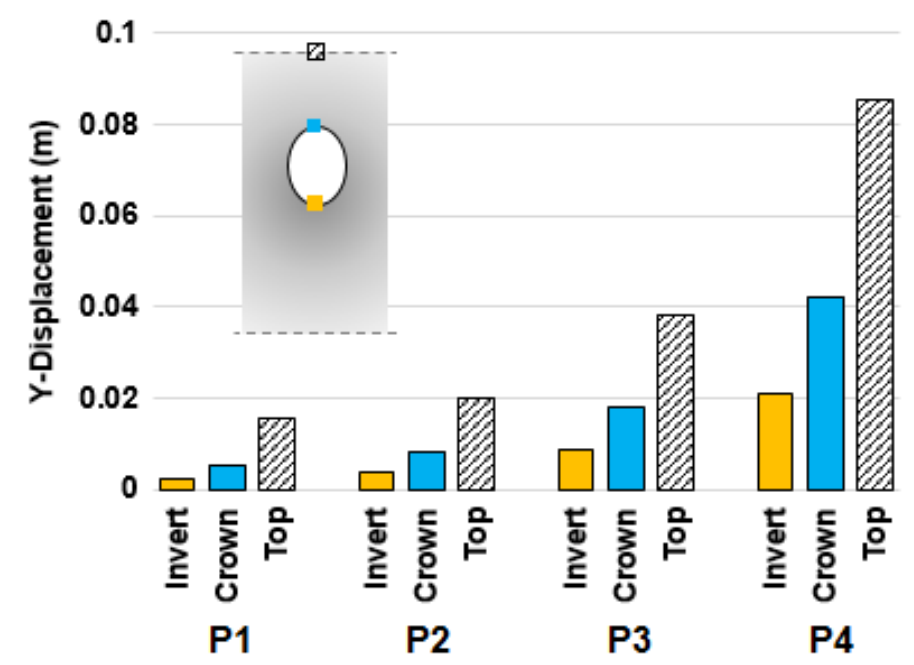

Figure 8. Y-Displacement values at the Invert, Crown and Top surface for P1, P2, P3 and P4

Figure 9 shows the distortions in the soil regions (with $5 \mathrm{x}$ times magnification) around the pipeline area when the simulation period has reached the $30^{\text {th }}$ day of rainfall infiltration for each initial soil suction profile. The deformed meshes indicate the magnitude and direction of the ground movements while the black ring indicates the original location of the pipe. Based on the comparison between the four deformed meshes (from P1 to P4), it is clear that deformations around the pipeline perimeter increase as the initial suction increases because of the increasing role of the soil suction that acts like a hydraulic stress that produce soil deformations which can be clearly seen in Equation 5 which correspond to the second member of the right hand side of the stress-strain relationship presented in Equation 2. 


$$
\left\{\begin{array}{c}
\Delta \varepsilon_{x \text { (suction })} \\
\Delta \varepsilon_{\text {y(suction })} \\
\Delta \gamma_{x y \text { (suction })}
\end{array}\right\}=\frac{1}{H}\left[\begin{array}{lll}
1 & 0 & 0 \\
0 & 1 & 0 \\
0 & 0 & 1
\end{array}\right]\left\{\begin{array}{l}
\Delta\left(u_{a}-u_{w}\right) \\
\Delta\left(u_{a}-u_{w}\right) \\
\Delta\left(u_{a}-u_{w}\right)
\end{array}\right\}
$$

Where, $\Delta \varepsilon_{x \text { (suction) }}, \Delta \varepsilon_{y \text { (suction) }}$ and $\Delta \gamma_{x y \text { (suction) }}$ are the normal and shear strain components with respect to the soil suction. Figures 9c and 9d showed that the soil at the pipeline crown and invert deformed significantly due to the high state of unsaturation in the suction P3 and P4, respectively, which induces a vertical displacement of the pipe. In the case of P1 and P2 the deformed meshes are presented in Figures 9a and 9b, respectively, for which the observed deformations mainly concern the crown of the pipeline due the limited expansion occurred at the pipeline invert mainly due to the low state of unsaturation of these two initial conditions.

A cross-section ovalization of the pipeline can be clearly observed in Figures 9b, 9c and 9d because the final vertical displacements (obtained at the $30^{\text {th }}$ days) at the crown of pipeline are higher than those of the invert which leads to an increase of the pipeline diameter in the vertical direction as can be observed from Figure 8 where the increase of the diameter in the vertical direction reaches 1 and $2.1 \mathrm{~cm}$ taking into account the profile P3 and P4, respectively $(\mathrm{GWT}=60$ and $120 \mathrm{~m})$. This is obviously associated with a decrease in diameter at the springline reaching a value of $2.04 \mathrm{~cm}$ in the case of the profile P4 $(\mathrm{GWT}=120 \mathrm{~m})$. Such behavior which is consistent with the findings of [18] and [23] can be attributed firstly to (1) the vertical direction of seepage as the upper zones saturate before the lower zones which is principally linked to the magnitude of suction with depth, SWCC and $K$ of the soil and secondly to (2) the volume change magnitudes which is proportional to the range of suction fluctuations. The same observations were made by Adem and Vanapalli [13] and Vu and Fredlund [14]. The profile P1, P2, P3 and P4 can represent different degrees of evapotranspiration during a dry season. As a result of this, it can be concluded from here that the higher the evapotranspiration or the depth of the water table the higher the induced distortions within the expansive soil mass and consequently the induced loading on the pipeline ring.

(a)

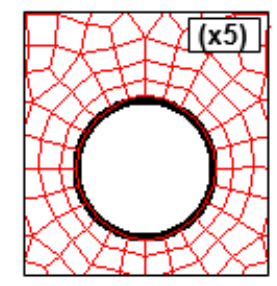

(b)

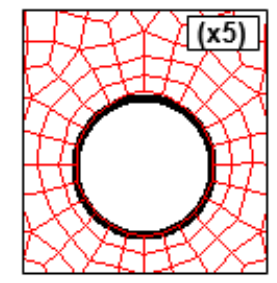

(c)

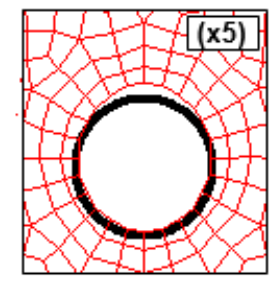

(d)

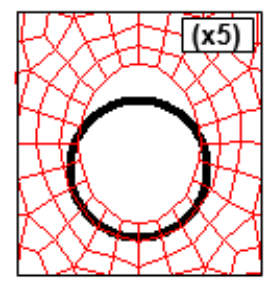

Figure 9. Deformed mesh around the pipeline perimeter (x5 magnitude)

\subsection{Radial Forces}

The obtained radial forces in the present analysis will be discussed considering those obtained in some previous studies carried out under other external loading such as unsupported excavation and frost heave in cold regions.

- Al-Khazaali et al. [20] used successfully SIGMA/W to investigate numerically the effect of a succession of unsupported excavations on nearby buried water transport pipeline considering of the effect of suction.

- Huang et al. [17] studied experimentally the circumferential induced strains and bending following vertical displacement due to frost heave in a permafrost.

\subsubsection{Axial Forces $\boldsymbol{F}_{\boldsymbol{A}}$}

The volume changes that occur in the expansive soil mass associated with heave at the top surface will result in stresses and strains on the pipeline ring and this will consequently lead to additional loads expressed in this study as pipeline internal forces $F_{A}, F_{S}$ and $M_{B}$.

The result of the axial forces $F_{A}$ along the perimeter of the Aine-Tine pipeline under different rainfall infiltration time durations at the chosen time steps $4,8,15$, and 30 days considered for the four initial suction profiles P1, P2, P3 and $\mathrm{P} 4$ are shown in Figure 10. It can be seen that positive values are obtained at the crown and invert (at angles $0^{\circ}$ and $180^{\circ}$ ) positions of the pipeline perimeter which means the development of axial compression forces for all the initial suction profiles while negative values appeared in the springline (right, $90^{\circ}$ and left, $270^{\circ}$ ) which means axial tension forces were developed in this location of the perimeter. Figure 10d shows the developed axial forces after 30 days of rainfall for the suction profile P4 which corresponds to the deepest GWT used in this study. The tension forces reached $67.26 \mathrm{kN}$ and $66.03 \mathrm{kN}$ at the crown and invert, respectively. The obtained values are $38 \%$ higher than those obtained after 15 days of simulation (Figure 10c) while the increase reaches $104 \%$ between 8 days (Figure $10 \mathrm{~b}$ ) and 15 days. Regarding the compressive axial forces, the magnitudes are slightly lower and the ratios are equal to $14 \%$ and $139 \%$ from 8days to 15 days and from 15 days to 30 days, respectively. Due to the downward vertical direction of 
infiltration flow, the obtained values at the crown location are a slightly higher than those obtained in the invert while they are identical at the left and right springline locations. The axial compression and tension forces proportionally increased with both the duration of the infiltration from 4 to 30 days and the initial soil suction profiles from P1 to P4. From the results of Figure 10, it can be concluded that for a shallow water table which corresponds to the results indicated by the red contours and a short period of rainfall, as in the case of 4 days (Figure 10a), the pipe ring will receive negligible axial forces.

The presented results reflect the behavior of the soil-pipeline system with respect to the rain time duration and the initial suction conditions. This can be ascribed to the soil suction contribution to the unsaturated behavior of the AineTine soil which is expressed as volume expansion. The decrease of the suction (see Figure 6) around the pipeline ring will produce stresses and strains at all nodes of the model following the rainfall infiltration. This will consequently, lead to an increase in tension axial forces at the crown and invert location. In contrast, the decrease of the soil suction with rainfall for all the cases P1, P2, P3 and P4 will also cause an increase in compression axial forces at the springline location. Similar observations have been reported by Alkhazaali et al. [20] however, the axial compressive forces were obtained at the springline location (i.e., $90^{\circ}$ and $270^{\circ}$ ) while tensile forces were obtained at the crown and invert locations (i.e., $0^{\circ}$ and $180^{\circ}$ ). This is due to the dominance of the horizontal displacements induced by a succession of unsupported vertical excavation operations unlike in the present study, the vertical displacements are dominant due to the expansion of the Aine-Tine soil upwards.

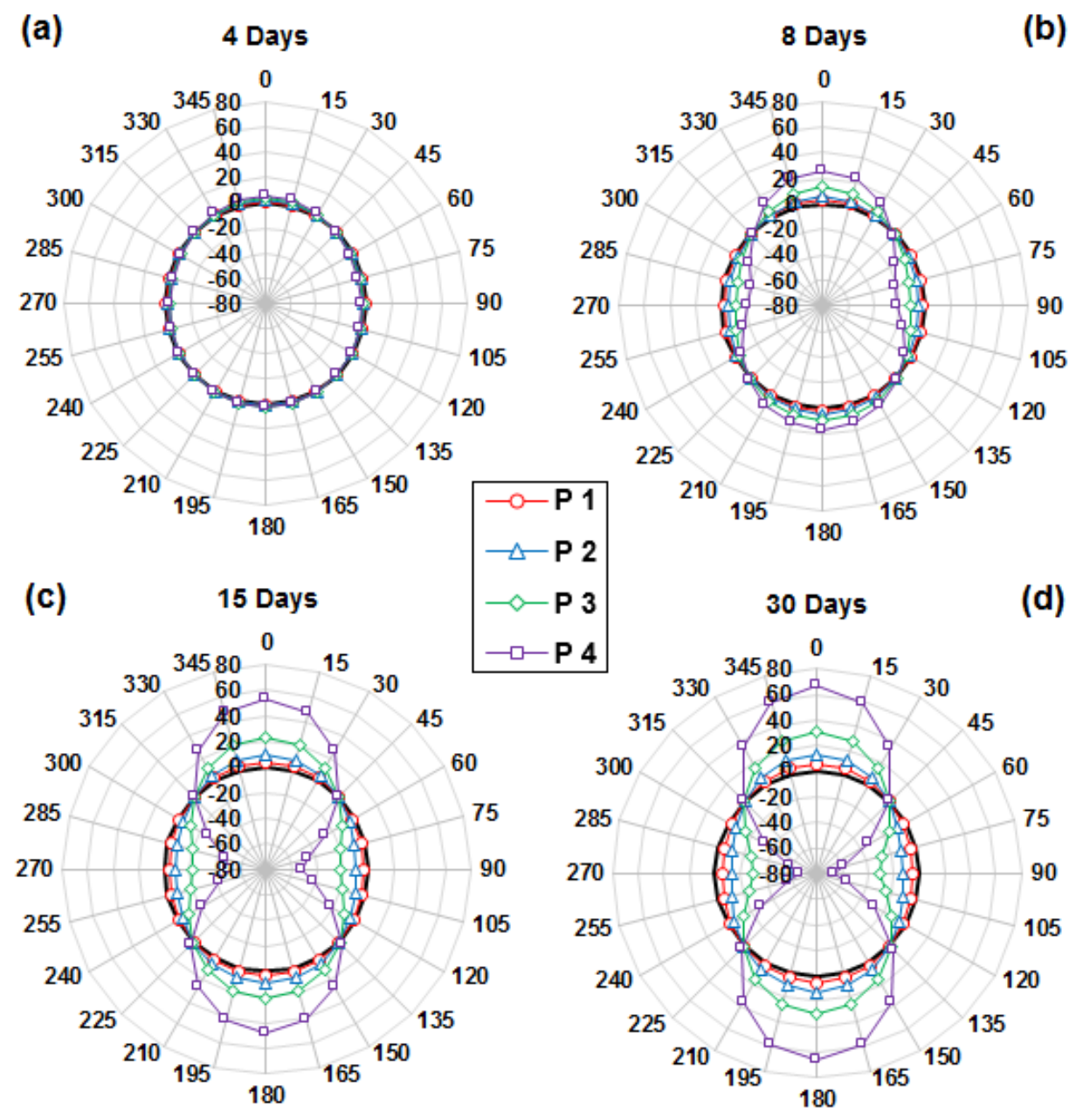

Figure 10. Axial force $F_{A}$ distribution along pipeline perimeter $(\mathrm{kN})$ with time

\subsubsection{Shear Forces $F_{S}$}

Figure 11 presents the variation of the circumferential shear forces $F_{S}$ along the cross section pipeline wall. The shear forces developed on the pipeline wall increase with the rainfall time duration. Where the maximum peak (Positive) values were calculated approximately at angles $30^{\circ}$ and $225^{\circ}$ while the minimum peak (Negative) values were calculated at angles $135^{\circ}$ and $330^{\circ}$ while those obtained by Al-Khazaali et al. [20] are located approximately in the same locations (Approximately $\pm 5^{\circ}$ ) with opposite signs and increase with the depth of excavation which has the same role as the downward flux which induces the vertical movements in the present analysis. Furthermore, the obtained shear forces have symmetrical distribution whereas those obtained by Al-Khazaali et al. [20] are higher in 
magnitude and much higher at the side close to the front of the excavation. This is due to the horizontal direction of the large sliding movements as discussed above. It can be noticed from each of the plotted curves of Figures 11a, 11b, $11 \mathrm{c}$ and $11 \mathrm{~d}$, that obviously the induced shear forces increase with respect to the initial suction profile $\left(u_{a}-u_{w}\right)$ conditions P1, P2, P3 and P4, which corresponds to different theoretical water table levels or may reflect different degrees of evapotranspiration which are very probable in arid and semi-arid climate such as the site of the present study. The magnitudes of the calculated shear forces are lower than those of the axial forces where as shown in Figures $11 \mathrm{a}, 11 \mathrm{~b}, 11 \mathrm{c}$ and $10 \mathrm{~d}$, the positive peak values for $\mathrm{P} 4$ (with purple color) calculated at the location $30^{\circ}$ are equal to $0.25,1.11,1.92$ and $2.32 \mathrm{kN}$ and those calculated at $225^{\circ}$ reached $0.04,0.41,1.4$ and $1.95 \mathrm{kN}$. The same observation about the change of magnitudes can be drawn regarding the influence of the duration and the depth of the GWT as for the axial forces.

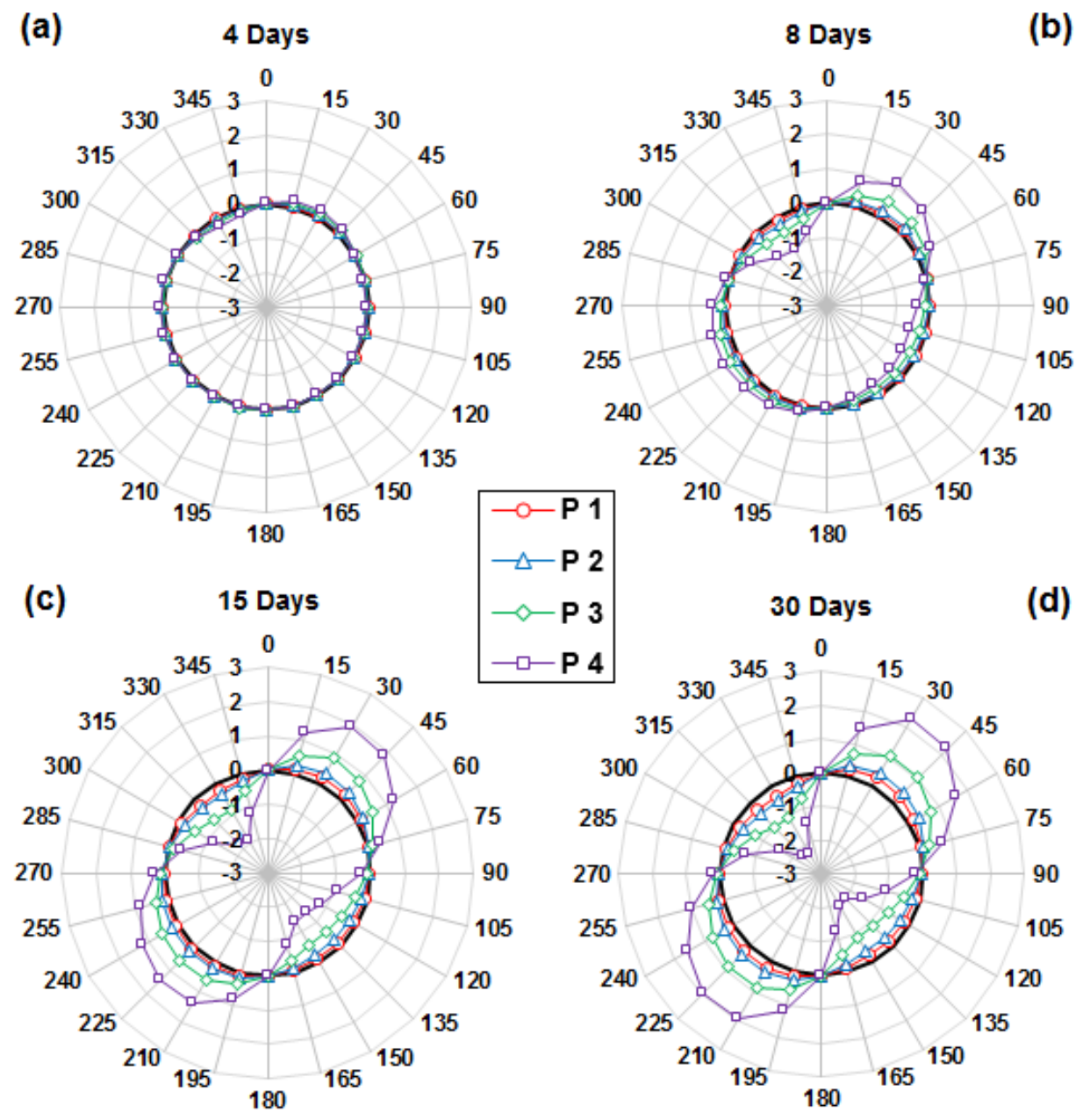

Figure 11. Shear force $F_{S}$ distribution along pipeline perimeter $(\mathrm{kN})$ with time

\subsubsection{Bending Moment $M_{B}$}

The bending moment results $M_{B}$ calculated along the pipeline perimeter are shown in Figure 12 using the color red, blue, green and purple to represent the results of P1, P2, P3 and P4, respectively. It is clear that they present a similar trend and present a consistent response as for the previous internal forces (axial and shear forces). The peak positive values were found at angles $90^{\circ}$ and $270^{\circ}$ while, for the peak negative values, they were found at angles $0^{\circ}$ and $180^{\circ}$ which are the similar location for the peak axial force values but with different signs. Regardless of the time duration chosen it can be observed that peak values of calculated bending moment $M_{B}$ increased almost twice between each two subsequent initial suction condition from P1 to P4 and have dissymmetric distribution (in Figures 12a, 12b, 12c, and 12d). Similar results in terms of trends but with different magnitudes are reported in [17] for buried gas pipelines in cold regions which experienced vertical movements caused by differential frost heaves leading to the generation of circumferential strains as well as bending moments which are worse in the transition zone between frozen and unfrozen soil. Based on the comparison between the results of the peak values plotted in Figure 12, it was found that regardless of the duration of the simulation or the depth of the GWT, the order with respect to the magnitudes is as follows: the crown $\left(0^{\circ}\right)$, springline $\left(90^{\circ}\right.$ and $\left.270^{\circ}\right)$ and the invert $\left(180^{\circ}\right)$ while the maximum values of bending moment are calculated using the profile P4 after 30 days of rainfall and they reach values, respectively, $0.51,0.41$ and 
0.38 kN.m. Reading attentively the Figure 11 and Figure 12, it can be seen that at zero shear stresses location, the peak values (positive and negative) of bending moments were obtained. From the obtained results, it obvious that the internal forces are sensitive to the variation of the soil suction following a rainfall event on high expansive soil such as the clay of Aine-Tine site.

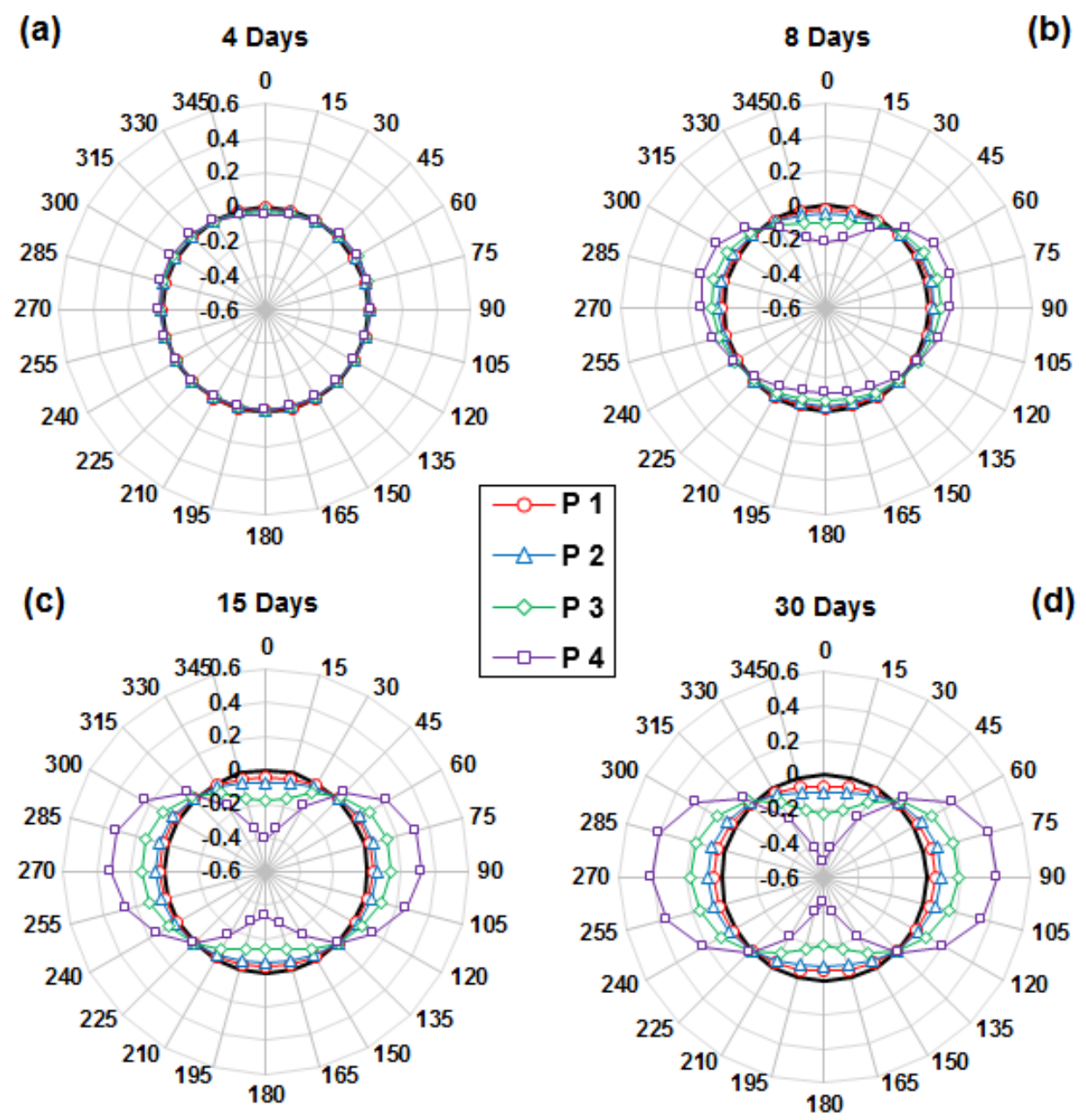

Figure 12. Bending moment $M_{B}$ distribution along pipeline perimeter $(\mathrm{kN})$ with time

\section{Conclusions}

In the present study, numerical analyses were performed to investigate the transverse structural behavior of buried pipelines in expansive soils considering the unsaturated behavior of soil under the effect of $4 \mathrm{~mm} /$ day rainfall precipitation lasting for 30 days as an external hydraulic loading. Considering the water supply $800 \mathrm{~mm}$ pipeline coming from the Beni-Haroun Dam and buried at $2 \mathrm{~m}$ depth in Aine-Tine (Mila, Algeria) high expansive soil, four simulations were performed to demonstrate the effect of the initial suction profiles P1, P2, P3 and P4 which may represent different degrees of aridity that characterize regions with arid and semi-arid climate.

The results obtained were expressed in terms of (1) changes in soil suction, (2) heave and deformations and (3) radial forces (Axial $F_{A}$, Shear $F_{S}$ forces and Bending moment $M_{B}$ ). Analysis of the results allowed to reach the following conclusions:

- Rainfall events can cause additional loads on buried pipelines in expansive soils because of the important role of the unsaturated behavior of such soils especially in arid and semi-arid regions.

- Due to the soil saturation process caused by the progressive rainfall infiltration water within the soil, the expansive soil exhibits volume changes associated with heave at the ground surfaces following decrease in suction indicating that the effect of the soil suction $\left(u_{a}-u_{w}\right)$ must be taken carefully into consideration, especially where the seasonal variation of moisture content is very high.

- The induced soil heave and the radial forces exerted on the pipeline wall (Axial, Shear and Bending moment) increase with the initial soil suction (P1, P2, P3 and P4) and also with the rainfall duration (4, 8, 15 and 30 days). 
- The initial suction values worked out from the water table depth or from the degree of evapotranspiration and the importance of the rainfall precipitation are important factors that impact seriously the unsaturated behavior of the soil behavior as well as the response of the pipeline structure.

- The pipeline cross-section ovalization can be the logic reason to many water leakage points along the paths of the Mila water supply pipelines including the one located in Aine-Tine site especially near the pipeline joints.

The results of the present study are very useful to understand the origin of the damages reported on the Ain-Tine water supply pipeline. The results of this study made clear that in order to achieve a realistic design of buried lifeline infrastructures, the unsaturated behavior of the embedding expansive soil should be taken into consideration under realistic climatic conditions of the region. Moreover, this study analyzed only the transverse behavior of the pipeline structure under simplified hypotheses. In order to achieve more realistic results, a representative daily precipitation data (i.e., intensity, duration and frequency) would be used instead. In addition, many types of the pipelines such as rigid, flexible, welded and jointed and with different diameter are buried to transport fluids and which need to be considered in the future studies. It would be also interesting to study the longitudinal behavior of the pipeline.

\section{Acknowledgements}

The first author gratefully expresses his appreciation to the Algerian Ministry of Higher Education and Scientific Research, which funded his PhD project. He also thanks the Universiti Teknologi Malaysia (UTM) for hosting his $\mathrm{PhD}$ attachment. Thanks are extended to Pr. Aminaton Marto (UTM) for her kind recommendations and to Mr. Abubakar Sadik Muhammed for his English language proof reading.

\section{Funding}

This research was funded by the Algerian Ministry of Higher Education and Scientific Research. Grant ID: PNE628-20192020

\section{Conflicts of Interest}

The authors declare no conflict of interest.

\section{References}

[1] Zhang, Xiong, and Jean-Louis Briaud. "Three Dimensional Numerical Simulation of Residential Building on Shrink-Swell Soils in Response to Climatic Conditions." International Journal for Numerical and Analytical Methods in Geomechanics 39, no. 13 (March 23, 2015): 1369-1409. doi:10.1002/nag.2360.

[2] Ozer, Mustafa, Resat Ulusay, and Nihat Sinan Isik. "Evaluation of Damage to Light Structures Erected on a Fill Material Rich in Expansive Soil." Bulletin of Engineering Geology and the Environment 71, no. 1 (August 30, 2011): 21-36. doi:10.1007/s10064-011-0395-2.

[3] Yilmaz, Işık. "The Effect of Swelling Clays on a Water Transport Canal Between Köklüce HPP and Erbaa HPP (Turkey)." Bulletin of Engineering Geology and the Environment 66, no. 4 (February 24, 2007): 467-472. doi:10.1007/s10064-007-00861 .

[4] Clark, Curtis M. "EXPANSIVE-SOIL EFFECT ON BURIED PIPE.” Journal - American Water Works Association 63, no. 7 (July 1971): 424-427. doi:10.1002/j.1551-8833.1971.tb04116.x.

[5] Robert, D. J., K. Soga, and T. D. O'Rourke. "Pipelines Subjected to Fault Movement in Dry and Unsaturated Soils." International Journal of Geomechanics 16, no. 5 (October 2016). doi:10.1061/(asce)gm.1943-5622.0000548.

[6] Uzundurukan, Soner, Sıddıka Nilay Keskin, Hüseyin Yıldırım, Turan Selçuk Göksan, and Ömür Çimen. "Suction and Swell Characteristics of Compacted Clayey Soils.” Arabian Journal for Science and Engineering 39, no. 2 (November 7, 2013): 747752. doi:10.1007/s13369-013-0852-2.

[7] Ito, Maki, Shahid Azam, and Yafei Hu. "A Two Stage Model for Moisture-Induced Deformations in Expansive Soils." Environmental Systems Research 3, no. 1 (June 24, 2014). doi:10.1186/s40068-014-0019-5.

[8] D. G. Fredlund et H. Rahardjo, Soil Mechanics for Unsaturated Soils. John Wiley \& Sons, 1993.

[9] Biot, Maurice A. “General Theory of Three - Dimensional Consolidation.” Journal of Applied Physics 12, no. 2 (February 1941): 155 - 164. doi:10.1063/1.1712886.

[10] Fredlund, D. G., and N. R. Morgenstern. "Constitutive Relations for Volume Change in Unsaturated Soils." Canadian Geotechnical Journal 13, no. 3 (August 1, 1976): 261-276. doi:10.1139/t76-029. 
[11] Kumar, Sanjeev, Anil Kumar Sahu, and Sanjeev Naval. "Influence of Jute Fibre on CBR Value of Expansive Soil." Civil Engineering Journal 6, no. 6 (June 1, 2020): 1180-1194. doi:10.28991/cej-2020-03091539.

[12] Han, Zhong, Sai K. Vanapalli, and Zehra Nil Kutlu. "Modeling Behavior of Friction Pile in Compacted Glacial Till." International Journal of Geomechanics 16, no. 6 (December 2016). doi:10.1061/(asce)gm.1943-5622.0000659.

[13] Adem, H H, and S K Vanapalli. "Constitutive Modeling Approach for Estimating1-Dheave with Respect to Time for Expansive Soils.” International Journal of Geotechnical Engineering 7, no. 2 (April 2013): $199-204$. doi:10.1179/1938636213z.00000000024.

[14] Vu, Hung Q, and Delwyn G Fredlund. "Challenges to Modelling Heave in Expansive Soils." Canadian Geotechnical Journal 43, no. 12 (December 1, 2006): 1249-1272. doi:10.1139/t06-073.

[15] Randeniya, Chamal, D.J. Robert, Chun-Qing Li, and Jayantha Kodikara. "Large-Scale Experimental Evaluation of Soil Saturation Effect on Behaviour of Buried Pipes Under Operational Loads." Canadian Geotechnical Journal 57, no. 2 (February 2020): 205-220. doi:10.1139/cgj-2018-0544.

[16] Robert, D. J., K. Soga, T. D. O'Rourke, and T. Sakanoue. "Lateral Load-Displacement Behavior of Pipelines in Unsaturated Sands." Journal of Geotechnical and Geoenvironmental Engineering 142, no. 11 (November 2016): 04016060. doi:10.1061/(asce)gt.1943-5606.0001504.

[17] Huang, Scott L., Kun Yang, Satoshi Akagawa, Masami Fukuda, and Shunji Kanie. "Frost Heave Induced Pipe Strain of an Experimental Chilled Gas Pipeline." Innovative Materials and Design for Sustainable Transportation Infrastructure (June 2015). doi:10.1061/9780784479278.037.

[18] Rajeev, Pathmanathan, and Jayantha Kodikara. "Numerical Analysis of an Experimental Pipe Buried in Swelling Soil." Computers and Geotechnics 38, no. 7 (November 2011): 897-904. doi:10.1016/j.compgeo.2011.06.005.

[19] Robert, Dilan, and Kenichi Soga. "Soil-Pipeline Interaction in Unsaturated Soils." Mechanics of Unsaturated Geomaterials (March 7, 2013): 303-325. doi:10.1002/9781118616871.ch13.

[20] Al-Khazaali, Mohammed, Sai K. Vanapalli, and Won Taek Oh. "Numerical Investigation of Soil-pipeline System Behavior Nearby Unsupported Excavation in Saturated and Unsaturated Glacial Till.” Canadian Geotechnical Journal 56, no. 1 (January 2019): 69-88. doi:10.1139/cgj-2017-0411.

[21] Vazouras, Polynikis, Panos Dakoulas, and Spyros A. Karamanos. "Pipe-soil Interaction and Pipeline Performance Under Strike-slip Fault Movements." Soil Dynamics and Earthquake Engineering 72 (May 2015): 48-65. doi:10.1016/j.soildyn.2015.01.014.

[22] Oghabi, Mohsen, Mehdi Khoshvatan, and Aminaton Marto. "Evaluation of the Response of Buried Steel Pipelines Subjected to the Strike-Slip Fault Displacement." Civil Engineering Journal 3, no. 9 (October 7, 2017): 661-671. doi:10.21859/cej03093.

[23] Saadeldin, Ramy, Yafei Hu, and Amr Henni. "Numerical Analysis of Buried Pipes Under Field Geo-Environmental Conditions.” International Journal of Geo-Engineering 6, no. 1 (June 26, 2015). doi:10.1186/s40703-015-0005-4.

[24] Wahid. Chettah, "Investigation des propriétés minéralogiques et géomécaniques des terrains en mouvement dans la ville de Mila « Nord-Est d'Algérie »”, Thèse de Magistère, University of Batna 1 Hadj Lakhdhar, Batna, Algérie, 2009.

[25] Athmania, Djamel, Abdelkader Benaissa, Achour Hammadi, and Mounir Bouassida. "Clay and Marl Formation Susceptibility in Mila Province, Algeria." Geotechnical and Geological Engineering 28, no. 6 (June 23, 2010): 805-813. doi:10.1007/s10706-010-9341-5.

[26] Azzedine. Mebarki. "HYDROLOGIE DES BASSINS DE L'EST ALGERIEN : RESSOURCES EN EAU, AMENAGEMENT, ET ENVIRONNEMENT" (2005 thèse de doctorat d'etat, University of Mentouri, Constantine.

[27] GeoSlope International Ltd, Sigma/W user's guide for stress-deformation analysis. GEO-SLOPE International Ltd, Calgary, AB, Canada, 2007.

[28] Al-Khazaali, Mohammed, and Sai K. Vanapalli. “A Novel Experimental Technique to Investigate Soil-Pipeline Interaction Under Axial Loading in Saturated and Unsaturated Sands.” Geotechnical Testing Journal 43, no. 1 (March 15, 2019): 20180059. doi:10.1520/gtj20180059.

[29] Qi, Shunchao, and Sai K. Vanapalli. "Hydro-Mechanical Coupling Effect on Surficial Layer Stability of Unsaturated Expansive Soil Slopes.” Computers and Geotechnics 70 (October 2015): 68-82. doi:10.1016/j.compgeo.2015.07.006.

[30] Bahrami Balfeh Teimouri, Atanaz, and Ahad Bagherzadeh Khalkhali. "Stability Control of Narmab Dam and Sensitivity Analysis of Reliability Coefficients." Civil Engineering Journal 4, no. 9 (September 30, 2018): 2197. doi:10.28991/cej03091150 . 
[31] Vu, Hung Q, and Delwyn G Fredlund. "The Prediction of One-, Two-, and Three-Dimensional Heave in Expansive Soils." Canadian Geotechnical Journal 41, no. 4 (August 1, 2004): 713-737. doi:10.1139/t04-023.

[32] van Genuchten, M. Th. "A Closed-Form Equation for Predicting the Hydraulic Conductivity of Unsaturated Soils." Soil Science Society of America Journal 44, no. 5 (September 1980): 892-898. doi:10.2136/sssaj1980.03615995004400050002x.

[33] Fredlund, D.G., and Anqing Xing. "Equations for the Soil-Water Characteristic Curve." Canadian Geotechnical Journal 31, no. 4 (August 1, 1994): 521-532. doi:10.1139/t94-061.

[34] Vazouras, Polynikis, Spyros A. Karamanos, and Panos Dakoulas. "Finite Element Analysis of Buried Steel Pipelines Under Strike-Slip Fault Displacements.” Soil Dynamics and Earthquake Engineering 30, no. 11 (November 2010): 1361-1376. doi:10.1016/j.soildyn.2010.06.011.

[35] Azam, Shahid, Imran Shah, Mavinakere E. Raghunandan, and Maki Ito. "Study on Swelling Properties of an Expansive Soil Deposit in Saskatchewan, Canada." Bulletin of Engineering Geology and the Environment 72, no. 1 (January 6, 2013): 25-35. doi:10.1007/s10064-012-0457-0.

[36] Oh, Won Taek, Sai K. Vanapalli, and Anand J. Puppala. "Semi-Empirical Model for the Prediction of Modulus of Elasticity for Unsaturated Soils.” Canadian Geotechnical Journal 46, no. 8 (August 2009): 903-914. doi:10.1139/t09-030.

[37] Zhang, Junhui, Junhui Peng, Jue Li, and Jianlong Zheng. "Variation of Resilient Modulus with Soil Suction for Cohesive Soils in South China.” International Journal of Civil Engineering 16, no. 12 (May 30, 2018): 1655-1667. doi:10.1007/s40999-018$0315-\mathrm{y}$.

[38] Adem, Hana H., and Sai K. Vanapalli. "Prediction of the Modulus of Elasticity of Compacted Unsaturated Expansive Soils." International Journal of Geotechnical Engineering 9, no. 2 (March 18, 2014): $163-175$. doi:10.1179/1939787914y.0000000050.

[39] Adem, Hana H., and Sai K. Vanapalli. "Elasticity Moduli of Expansive Soils from Dimensional Analysis." Geotechnical Research 1, no. 2 (June 2014): 60-72. doi:10.1680/gr.14.00006.

[40] Qi, Shunchao, and Sai K. Vanapalli. "Influence of Swelling Behavior on the Stability of an Infinite Unsaturated Expansive Soil Slope.” Computers and Geotechnics 76 (June 2016): 154-169. doi:10.1016/j.compgeo.2016.02.018. 